\title{
Forehead stimulation decreases volume of the infarction triggered by permanent occlusion of middle cerebral artery in Rats
}

\begin{abstract}
Background: Universally present in animals diving response triggered by stimulation of the trigeminal nerve is known as "oxygen conserving reflex". This powerful integrative response includes apnea, bradycardia, and blood flow redistribution targeted to protect the brain against hypoxia. We hypothesized that diving response triggered by forehead stimulation can be neuroprotective in rat
\end{abstract}

Methods: Male Sprague-Dawley rats were anesthetized, intubated, and artificially ventilated while blood gases and body temperature were maintained at physiologic levels. Arterial pressure, heart rate and temperature and in some cases, CBF were monitored. The forehead skin selectively was continuously selectively cooled or electrically stimulated for one hour. Middle cerebral artery was permanently occluded and infarction volume was determined 24 hours later.

Results: Forehead cooling to $+11^{\circ} \mathrm{C}$ decreased infarction volume by $31 \%$ compared to control $(58 \pm 14 \mathrm{~mm} 3$ vs. $87 \pm 12 \mathrm{~mm} 3$, corrected for edema, $\mathrm{p}<0.05)$. Electrical stimulation of the forehead decreased infarction volume by $65 \%$ (30 $17 \mathrm{~mm} 3$ vs. $81 \pm 10 \mathrm{~mm} 3$ corrected for edema, $\mathrm{p}<0.01$ ) while temporal muscle temperature remained unchanged. Blood gases, body temperatures were comparable in all groups. Forehead cooling alone triggered changes in arterial pressure and cerebral blood flow comparable to changes observed during diving response in rats.

Conclusion: Stimulation, temperature or electrical, of the forehead in rats decreases volume of the infarction produced by permanent occlusion of middle cerebral artery. Diving response may have neuroprotective component, and its activation can be beneficial for brain protection.

Keywords: Ischemic stroke, Diving response, Therapeutics, Electric stimulation, Hypothermia, Neurogenic neuroprotection
Volume 2 Issue 5 - 2015

\author{
James M Shiflett,' Andrew D Parent,' Gavin \\ W Britz, ${ }^{2}$ Eugene V Golanov ${ }^{1,2}$ \\ 'Department of Neurosurgery, University of Mississippi Medical \\ Center, USA \\ ${ }^{2}$ Department of Neurosurgery, The Houston Methodist \\ Hospital, USA
}

Correspondence: Eugene V Golanov, M.D., Ph.D., The Houston Methodist Hospital, 656 Fannin Str., Suite 944, USA, Tel 7|3-44I8692, Fax 7।3-790-3075,

Emailevgolanov@houstonmethodist.org

Received: July 05, 2015 | Published: August 28, 2015

\section{Introduction}

In spite of numerous investigative efforts, finding efficient therapy for the ischemic stroke remains elusive. ${ }^{1,2}$ Naturally occurring wellestablished phenomena of "preconditioning" and "postconditioning" suggest the existence of internal neuroprotective mechanisms. Recruitment of internal neuroprotective mechanisms provides attractive alternative for the existing methods ${ }^{5-7}$ Currently, most often internal neuroprotective mechanisms or endogenous neuroprotection are activated by exposure either to sublethal damaging factors, such as ischemia, or by stimulation of selective brain structures. ${ }^{8-10}$

Here we explored neuroprotective potential of naturally occurring defensive mechanism known as diving response. Practically all mammals, including humans, during lifetime face situations with decreased oxygen supply such as diving, and developed a stereotypical response geared toward the surviving of hypoxia. ${ }^{11-13}$ Excitation of trigeminal (V1) or glossopharyngeal nerves, which innervate eyes, nose, and face, triggers complex systemic reaction, which is known as diving reflex or diving response. ${ }^{13-18}$ Diving response consists of highly coordinated increase in AP, decrease in cutaneous blood flow, expiratory apnea, bradycardia and increase of cerebral blood flow $(\mathrm{CBF}) .{ }^{11,19}$ Diving response seems to be present not only in humans or diving mammals but in all vertebrates..$^{13,20,21}$ As diving response allows animals to survive in anoxic conditions longer than expected, it was called by Wolf oxygen-conserving reflex. ${ }^{22}$
In humans, just forehead cooling is sufficient to trigger "diving reflex", ${ }^{18}$ which is oxygen conserving ${ }^{23}$ and suggested to be protective ${ }^{24}$ promoting survival after near drowning. ${ }^{25}$

We hypothesize that activation of the facial areas innervated by the first branch of the trigeminal nerve may have neuroprotective effect. Here we demonstrate that stimulation of the forehead in rats, area innervated by the trigeminal nerve, ${ }^{26}$ effectively decreases volume of the brain infarction triggered by permanent middle cerebral artery occlusion (MCAO).

\section{Materials and methods}

Experiments were performed on adult male (350-400g) SpragueDawley rats. All experiments were performed in accord with the "Guide for the Care and Use of Laboratory Animals (Institute for Laboratory Animal Research, National Research Council. Washington, DC: National Academy Press, 1996) and approved by University of Mississippi Medical Center IACUC, protocol \# 1009. All surgical procedures were performed aseptically. After initiation, animals were intubated and anesthesia was maintained with $1.5-1.8 \%$ isoflurane in gas mixture of $20 \% \mathrm{O} 2$ and $80 \% \mathrm{~N} 2$ using small animal respirator (SAR 830/P, ITC Inc, CA, USA). The depth of anesthesia was monitored by observing AP and corneal reflex. Femoral arteries were catheterized for continuous recording of AP (AD Instruments, CO, USA) and arterial blood gases monitoring (blood-gas analyzer, ABL5, Radiometer, Copenhagen, Denmark). Body temperature was 
monitored and maintained at normal levels using thermo pad feedback (908100-OPT-HB, TSE Systems MI, USA).

Rats were mounted in a stereotaxic apparatus (Kopf, Tujunga, CA, USA). To monitor the cerebral blood flow (CBF) the calvarium was exposed, and laser-Doppler flowmeter (Periflux PF3, Perimed $\mathrm{AB}$, Jarfalla, Sweden) probe (tip diameter $0.45 \mathrm{~mm}$ ) was placed over the parietal cortex after thinning the bone with a cooled drill to create rectangular window $(3 \times 4 \mathrm{~mm})$. Subdermal forehead and temporal muscle temperatures were monitored continuously using thermoprobes (thermocouple 24 Ga, Physitemp, NJ, USA) introduced subcutaneously through the needle and recorded by data logger (ADInstruments, CO, USA).

To induce ischemic infarction we employed widely used distal occlusion mode ${ }^{27}$ routinely used in our previous experiments. ${ }^{28-31}$ In short, MCA was exposed through the temporal craniotomy. Small cut was made in dura along the MCA. Thin stainless steel wire $(0.2 \mathrm{~mm}$ diameter) hook was inserted under the artery at the point just proximal to the lenticulostriate branches. The artery was lifted by the hook. The wire was carefully heated by the cautery while care was taken to avoid thermal damage of the underlying brain tissue. The artery was thus cauterized and proximal and distal segments were separated to prevent recanalization. The wound was closed. At the end of the experiment, anesthesia was discontinued. The animal was returned to the home cage. Twenty-four hours later, rat was deeply anesthetized and euthanized. Brain was removed, frozen and serially sectioned coronally every $400 \mu \mathrm{m}$ at $20 \mu \mathrm{m}$ thickness in a cryostat and stained with thionine for Nissl substance. Staining with thionine of Nissl substance is widely used to delineate the core of the infarction as early as 2 hours after the infarction. ${ }^{32}$ Due to chromatolysis in damaged neurons the core of the infarction is clearly brightened and demarcated from the surviving cell. The cross-sectional area of the lesion (characteristic sharp delineation of loss of Nissl-staining by damaged cells) was digitized using MCID-Elite software (Amersham Biosciences Corp, Piscataway, NJ, USA). The lesion volume was estimated by investigator blinded to the specific experiment. Infarction volume subsequently was corrected for edema (infarction volume* (volume of contralateral hemisphere/volume of infarcted hemisphere) $){ }^{33}$

Cooling of the forehead was achieved by using specially designed cooling device. Cooling device was made of coiled copper tubing (diameter $3 \mathrm{~mm}$ ) with overall diameter of the coil of $2 \mathrm{~cm}$. Water circulated through the coil was chilled to $10{ }^{\circ} \mathrm{C}$ by temperature controller (CL-100, Warner Instruments, LLC, Hamden, CT, USA). The cooling device attached to the holder was placed on the preshaved forehead skin only to touch it without excessive pressure.

Electrical stimulation (rectangular cathodal pulses, $0.5 \mathrm{~ms}, 60 \mu \mathrm{A}$ $25 \mathrm{~Hz}$, stimulator model 2100, A-M Systems, Seattle WA, USA) was delivered through two stainless steel needles (24GA) placed subcutaneously bilaterally along the lines connecting ear and eye.

Cooling or electrical stimulation was committed just before craniotomy for MCA occlusion (MCAO), lasted during the occlusion (10-15 $\mathrm{min})$ and for one hour afterwards. After that, wounds were closed and animal was returned to the home cage. In control animals, temperature of circulating water was maintained at $36{ }^{\circ} \mathrm{C}$ for the same period of time. In another control group, needles were inserted as described but no electrical stimulation was delivered.

Statistics: Data were expressed as mean \pm SEM. Comparisons were made using ANOVA with least significant difference post-hoc analysis or paired samples T-test, when appropriate. Differences were considered significant at $\mathrm{p}<0.05$.

\section{Results}

\section{Effects of the forehead stimulation on the volume of the infarction triggered by MCAO}

Infarctions produced by occlusion of MCA: Volumes and distribution of the ischemic infarctions in both control groups (temperature or electrical stimulation control groups) were comparable and pooled together for the subsequent analysis. In the first control group (temperature stimulation control group, $\mathrm{n}=4$ ) temperature of circulating water was adjusted to maintain subcutaneous forehead temperature at $36{ }^{\circ} \mathrm{C}$. In the second control group (electrical stimulation control group, $n=4$ ) instrumented for the electrical stimulation, forehead temperature remained stable at $35 \pm 1$ ${ }^{\circ} \mathrm{C}$. After initiation of water circulation or needle introduction MCAO was performed. After MCAO MAP gradually increased maximally by $8 \%$ at $45 \min (p>0.05)$ and returned to the baseline at the end of the one-hour observation period (Figure1A). HR remained unchanged (Figure 1B). Temporal muscle temperature in both control groups was stable at $35 \pm 1{ }^{\circ} \mathrm{C}$.
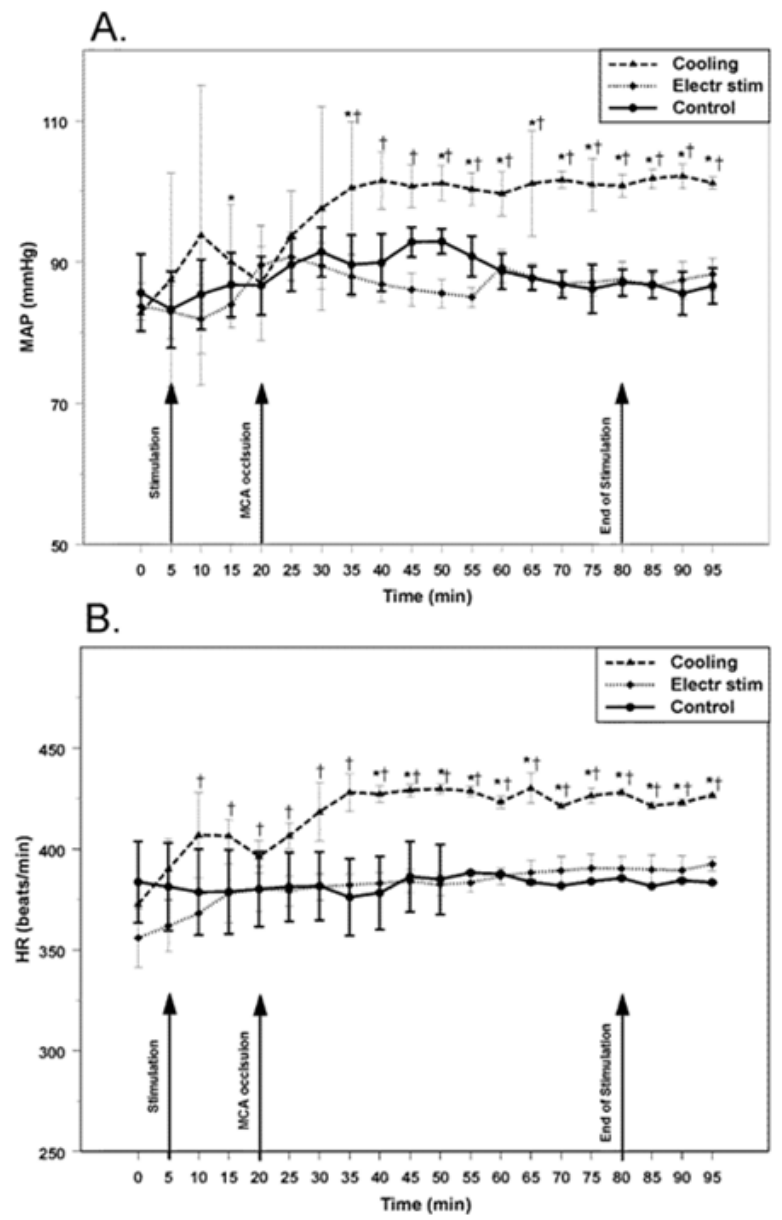

Figure I Changes in mean arterial pressure (MAP, upper panel) and heart rate (HR, lower panel) in rats in response to cold (Cooling, $n=5)$; electrical (Electr stim, $n=5)$; and sham (Control, $n=8$ ) stimulation of the forehead combined with middle cerebral artery occlusion. Arrows indicate beginning of stimulation, occlusion of middle cerebral artery and end of stimulation, respectively. $*$ - $p<0.05$, compared to baseline; $\nmid-p<0.05$, compared to other groups. 
Volume of the infarction core produced by MCAO averaged at $85 \pm 11 \mathrm{~mm} 3(87 \pm 12 \mathrm{~mm} 3$ and $81 \pm 10 \mathrm{~mm} 3, \mathrm{p}>0.1$, cooling and electrical stimulation control groups, respectively) as determined 24 hours after the occlusion (Figure 2). At the level of maximum damage, the lesion extended from primary motor cortical area to the piriform cortex, and to the outer sections of the caudate-putamen. In the rostrocaudal axis, the lesions involved large portions of the parietal, insular, temporal and occipital cortices (Figure 3,4).

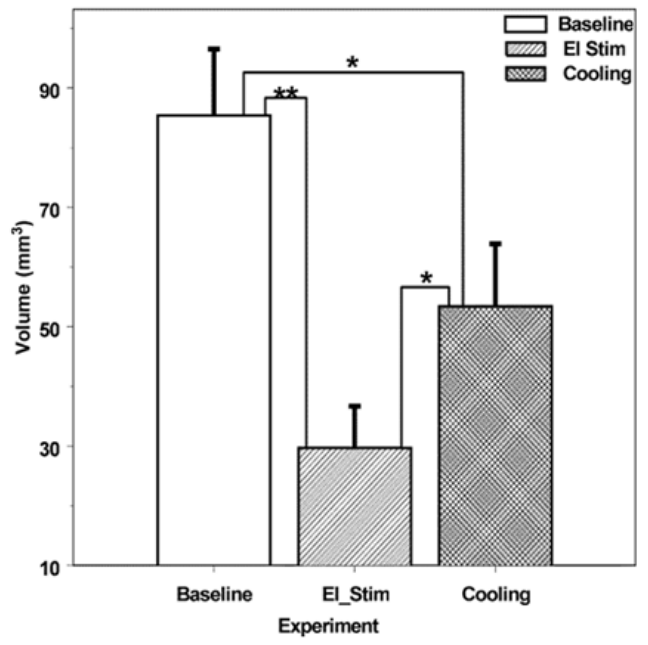

Figure 2 Comparative volume of the infarctions (corrected for edema) resulted 24 hours after permanent middle cerebral artery occlusion in control rats (Baseline, $n=8)$, in rats in which forehead were stimulated with electric current (El Stim, $n=5$ ) and in rats, in which forehead was cooled to $11{ }^{\circ} \mathrm{C}$ (Cooling, $n=5)$. * $-p<0.05 ; * *-p<0.01$.

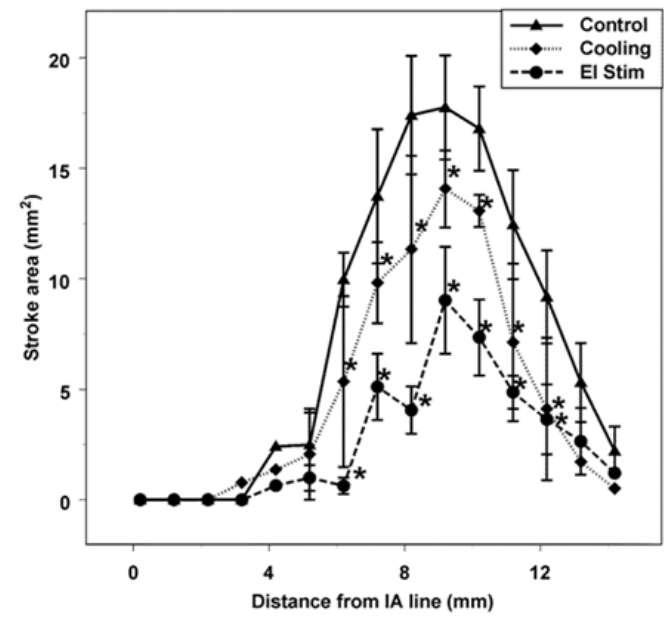

Figure 3 Distribution of the infarction area at the crossections of the brain at different distance from the interaural line after middle cerebral artery occlusion in the rats which received sham (Control, $n=8$ ), temperature (Cooling, $n=5$ ) or electrical (El Stim, $n=5$ ) stimulation of the forehead as measured 24 hours after the occlusion. Distance indicates distance from the interaural line in $\mathrm{mm}$. ${ }^{*}-\mathrm{p}<0.05$, compared to sham stimulated group.

\section{Effects of the forehead cooling on the focal ischemic lesions}

Cooling of the forehead to subdermal forehead temperature of 11 ${ }^{\circ} \mathrm{C}$ significantly $(\mathrm{p}<0.05, \mathrm{n}=5)$ reduced the volumes of focal ischemic infarctions by $31 \%$ to $58 \pm 14 \mathrm{~mm} 3$ (Figure 1). The salvage resulted from a decrease of the infarction volume prevalently in caudal regions of the ischemic lesion (Figure 3,4). During the cooling period rectal temperature remained at $36 \pm 1{ }^{\circ} \mathrm{C}$, temporal muscle temperature was stable at $33 \pm 1{ }^{\circ} \mathrm{C}$. MAP increased significantly by $8 \%(\mathrm{p}<0.05)$ compared to the baseline after the initiation of cooling, increased further by $22 \%(p<0.05)$ in $20 \mathrm{~min}$ after MCAO and remained elevated during the period of observation (Figure 1A). HR increased after the initiation of cooling by $9 \%(p<0.05)$, increasing further to reach maximum of $15 \%(\mathrm{p}<0.05)$ and remained elevated (Figure 1B) during the period of observation.

Effects of the subcutaneous electrical stimulation of the forehead on the focal ischemic lesions: Volume of the ischemic infarction core in rats $(\mathrm{n}=5)$, with electrical stimulation of the forehead averaged at $30 \pm 7 \mathrm{~mm} 3$ (corrected for edema): decrease of the infarction volume by $65 \%(p<0.01)$ (Figure 2) compared to matching control. The distribution of salvaged tissue in the forehead-stimulated rats was located at the periphery of the infarction, with most salvage located to the caudal areas of the infarction (Figure 3,4). During the stimulation period rectal temperature remained at $36 \pm 0.5^{\circ} \mathrm{C}$ and temporal muscle temperature was stable at $35 \pm 1{ }^{\circ} \mathrm{C}$. MAP and HR changes were nonsignificant (Figure 1A,B).

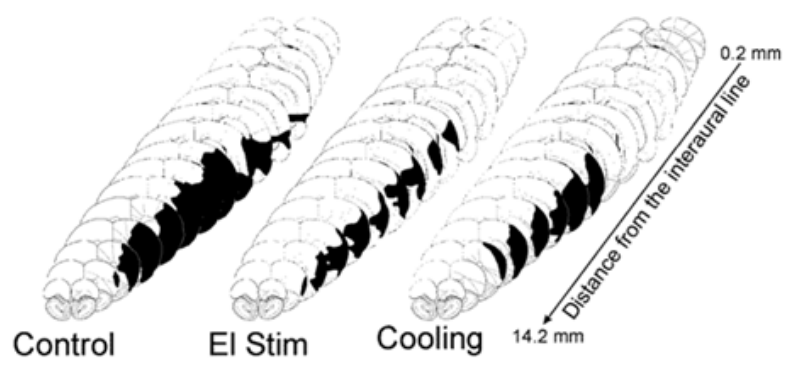

Figure 4 Representative distribution of the infraction (black areas) at different brain levels after permanent middle cerebral artery occlusion in rats received sham (Control), electrical (El Stim), or temperature (Cooling) stimulation of the forehead.

Blood gases $(\mathrm{PaCO} 2, \mathrm{PaO} 2$, and $\mathrm{pH})$ did not differ between groups: $\mathrm{pH}, 7.44 \pm 0.02 ; \mathrm{PaCO} 2,38.6 \pm 2.4 \mathrm{mmHg}$; $\mathrm{PaO} 2,129.6 \pm 31.1$ $\mathrm{mmHg}(\mathrm{mean} \pm \mathrm{SEM})$.

\section{Effects of forehead cooling on physiological variables}

In the additional group of animals $(n=4)$ we monitored the effects of selective forehead cooling on MAP, HR, and cortical CBF without MCAO. Following surgery and 10 minutes stabilization, cooling of the forehead was committed for 10 minutes; and rats were followed up for additional 10 minutes after the end of stimulation. Within 1 minute after the initiation of cooling, subcutaneous forehead temperature decreased to $11^{\circ} \mathrm{C}$. Forehead temperature returned to normal $\left(35^{\circ} \mathrm{C}\right)$ in 2 minutes termination of cooling. In parallel, MAP increased from $95 \pm 6 \mathrm{mmHg}$ to a maximum of $101 \pm 6(\mathrm{p}<0.05) \mathrm{mmHg}$ in 2 minutes. MAP remained elevated for the next 3 minutes and decreased slowly while remaining slightly above the baseline level for the rest of the experiment (Figure 5A). HR slightly increased by $2 \% \quad(\mathrm{p}<0.05)$ (from $385 \pm 6$ to $389 \pm 5$ beats/min), remained elevated for the next 3 minutes before returning to the baseline (Figure 5C). After cooling initiation, CBF rapidly increased to a maximum of $41 \pm 16 \%(\mathrm{p}<0.05)$ in 5 minutes and started to decline returning to the baseline in 10 minutes (Figure 5B). In parallel with $\mathrm{CBF}$ increase, $\mathrm{CVR}$ (CBF/MAP ratio) dropped to a minimum of $-23 \pm 7 \%(\mathrm{p}<0.05)$ gradually returning to the baseline in 10 minute (Figure 5D). The period of cooling was limited to 10 minutes due to the spontaneous return of the CBF to the baseline. In control group of three similarly instrumented animals 
monitored for the same period of time (20 minutes), no changes in MAP, HR, CBF or CVR were observed.
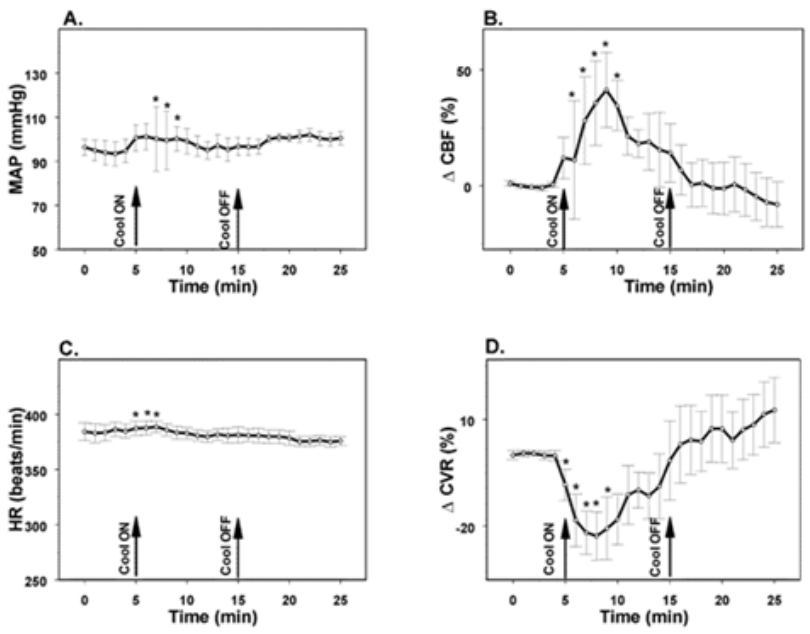

Figure 5 Changes in mean arterial pressure (MAP, A), heart rate $(H R, C)$, parietal cerebral blood flow (CBF, B) and parietal cerebrovascular resistance $(C V R, D)$ evoked by cooling of the forehead to $11{ }^{\circ} \mathrm{C}$ in rats. $*_{-} \mathrm{p}<0.05$, compared to the baseline, $n=4$. Arrows indicate onset $(\mathrm{Cool} O N)$ and end of cooling (Cool OFF) of the forehead.

\section{Discussion}

\section{Methodological considerations}

The major goal of our experiments was to evaluate effects of trigeminal stimulation on the survivability of brain parenchyma under condition of permanent ischemia. It is suggested that the latter model may better reflect the therapeutic potential of treatment compared to ischemia/reperfusion model. ${ }^{34}$ Thus in our experiments we employed model of permanent MCA occlusion.

In our experiments, temperature or electrical stimulation of the forehead in rat significantly decreased, by $31 \%$ and $60 \%$, respectively, the volume of the brain infarction triggered by permanent occlusion of MCA. The volume and distribution of focal ischemic infarctions in sham stimulated (control) rats were comparable to the infarctions described previously ${ }^{31-36}$ indicating that our model is similar to generally used for evaluation of neuroprotective manipulations.

Decrease of the infarction volume core observed in animals in which forehead was stimulated was attributable to the preservation of brain tissue: it was still significant after correcting for edema, in agreement with previous observations ${ }^{33}$ and coincided with the periphery of the infarcted area. ${ }^{36}$ The possible protective effect of isoflurane could be also ruled out. Data on the protective effect of isoflurane are controversial; it can exert protective effect ${ }^{37,38}$ or aggravate neuronal damage ${ }^{39}$ However, all our animals were under the same level of anesthesia for the comparable period of time and possible effects of isoflurane would be expected to affect results similarly. Nonetheless, we cannot exclude the possibility that stimulation-induced neural mechanisms of salvage could be affected by isoflurane differently.

The decrease in the infarction volume cannot be attributed to the differences in blood gases or body temperature, which were controlled and comparable in all groups of rats. Previously reported sympathetic activation accompanied by increase HR, MAP and blood catecholamines levels following MCAO due to the insular cortex ischemia was not observed in our experiments in control sham stimulated animals. The differences are probably due to the use of isoflurane in our experiments, which is known to suppress sympathetic activation and depress MAP. ${ }^{40-44}$

\section{Comparison of electrical and cooling stimulation salvaging effects}

The maximum salvaging effect in our experiments was afforded by the electrical stimulation of the forehead. Electrical stimulation employed in our experiments did not significantly affect MAP, HR, or forehead and temporal muscle temperatures, which remained comparable to such of control animals. These findings indicate that overall physiological state of the animals was not significantly affected by the local electrical stimulation of the forehead skin, and suggest that other than changes in MAP, HR or temporal muscle temperature factors were involved in neuroprotection.

Facial hairy skin in rats contains lanceolate, Ruffini and free nerve endings. ${ }^{26}$ Electrical stimulation at the parameters used excites multiple nerve endings, while cooling preferentially stimulates free nerve endings, which are thermosensors..$^{45}$ In our experiments electrical stimulation, i.e. activation of nerve endings of different modalities, exerted most pronounce neuroprotective effect strongly suggesting that, first: hypothermia is not the main neuroprotective factor, and, second, excitation of other than cold sensitive nerve endings or combination of activation of nerve endings of multiple modalities provides maximum neuroprotection.

Cold stimulation of the forehead is accompanied by sympathetic activation, increase in MAP, and bradycardia. ${ }^{14,46}$ Observed increase in MAP and CBF in response to cold stimulation of the forehead is consistent with the diving-induced autonomic changes. ${ }^{11,18}$ Diving response is a powerful integrative response and includes apnea, bradycardia, and redistribution of blood flow,,$^{11,18,19}$ which is initiated by the excitation of the ophthalmic division of the trigeminal nerve. In humans dipping of the face into cold water is sufficient to initiate typical diving response. ${ }^{13,14}$ Our observations that temperature stimulation of the forehead in rats triggers autonomic changes resembling diving response and has neuroprotective effect suggest that diving response itself has neuroprotective component. In our experiments forehead cold stimulation elevated MAP and HR compared to other groups. While cold-induced sympathetic activation seems not to be affected by isoflurane ${ }^{47}$ it's vagolytic effect may explain the lack of bradycardia observed in our experiments. ${ }^{48,49}$ Another possibility is that bradycardia response was attenuated by artificial respiration, which is in line with observations that apnea potentiates diving-induced bradycardia. ${ }^{50}$

Importantly, electrical stimulation of the forehead produced even more pronounced neuroprotection without significant autonomic component. Lack of autonomic component in response to electrical stimulation at the parameters of the forehead used in our experiments can be a result of simultaneous excitation of medullary dorsal horn neurons of different modalities. ${ }^{51,52}$ It is conceivable that excitation of neurons other than those excited by nociceptive $\mathrm{A} \delta$ and C-fibers may counter balance autonomic changes triggered by the latter. ${ }^{51,53}$

It was suggested that diving reflex could be an important component promoting survival after near drowning. ${ }^{25}$ Our experiments strongly suggest that forehead stimulation, which is capable to induce physiological response resembling the diving response, is neuroprotective, and most probably has other than hypothermia mechanisms. First, cooling was highly localized to the forehead while temporal muscle temperature, which is used to estimate brain temperature, ${ }^{54,55}$ was not significantly affected. Second, electrical stimulation of the forehead, which did not affect temporal muscle temperature, afforded even more pronounced salvage than cooling 
alone. These findings allow concluding that excitation of the nerves of the ophthalmic division of the trigeminal nerve innervating forehead produces salvaging effect.

\section{Possible mechanisms of forehead stimulation-induced neuroprotection}

Mechanisms mediating forehead stimulation-induced salvage are presently unknown. Previously it was demonstrated that stimulation of the trigeminal nerve increases CBF probably through the CGRPcontaining terminals innervating meningeal blood vessels. ${ }^{56-58}$ Selective cold stimulation of the forehead in our experiments produced significant elevation of CBF paralleled by decrease in CVR in accord with the previous findings..$^{14,59,60}$ However, CBF returned to the baseline within 10 minutes after the initiation of cold stimulation suggesting that $\mathrm{CBF}$ increase is not the leading mechanism of neuroprotection as we suggested earlier. ${ }^{36}$

We suggest that other than CBF increase mechanisms, such as neurogenic neuroprotection, ${ }^{8,61}$ are involved in the diving response associated neuroprotection. Besides well-established neuroprotective effect of cerebellar fastigial nucleus stimulation which offers long lasting (up to three weeks) ${ }^{31} \mathrm{CBF}$ - or cerebral glucose metabolismindependent neuroprotection ${ }^{62}$ the neurogenic neuroprotection can also be evoked by stimulation of subthalamic vasodilator area, ${ }^{63}$ and dorsal periaqueductal gray. ${ }^{28}$ Conceivably ventral thalamus ${ }^{64}$ and laterodorsal column of periaqueductal grey ${ }^{65}$ receiving projections from the medullary dorsal horn trigeminal inputs can activate innate neuroprotective mechanisms.

Endogenous neuroprotective mechanisms or neurogenic neuroprotection may include various factors such as opening of potassium channels, upregulation of uncoupling proteins and mitochondrial protein prohibitin, DNA repairing enzymes, and promote tissue repair mechanisms (recently reviewed (Wang et al., 2014). ${ }^{10}$

\section{Experimental limitations}

There are several limitations in our experiments. First, the infarction volume was determined only at one time point following the experiment ( 24 hours). In the future, it will be important to determine whether volume of the infarction remains smaller at longer times following the insult. Second, behavioral recovery evaluation needs to be performed to establish whether stimulation also promotes functional recovery early after the insult and at the later time. Third, optimal parameters for electrical stimulation need to be established. Fourth, it is imperative to establish time window following the MCAO during which forehead stimulation still is capable to decrease the infarction volume and improve recovery. These questions are currently being addressed in our investigations.

\section{Conclusion}

Here we demonstrate that cold or electrical stimulation of the forehead in the rat significantly decreases infarction volume following permanent MCA occlusion. Moreover, the electrical stimulation produced significantly more pronounced effect than cooling. We suggest that stimulation of the forehead activates endogenous neuroprotective mechanisms related to natural diving response universal to vertebrates. Activation of the endogenous protective mechanisms can offer significant neuroprotection in situations like stroke, brain trauma, and cardiac arrest and open the possibility to develop simple and useful methods for the treatment or prevention of brain damage. Just application of ice bag on the forehead in humans can simulate diving response and thus activate innate neuroprotective mechanism. ${ }^{66}$

The possible beneficial role of the diving response activation in humans is suggested by the reports of full recovery after people were submerged under water for prolonged periods of time (over one hour in some cases). ${ }^{67-70}$ Clinical observations suggest that survival after near drowning is not entirely attributable to the often-observed hypothermia: successful resuscitation was achieved at near normal body temperature ${ }^{67}$ and chances for resuscitation do not correlate with body temperature. ${ }^{71}$

Our observations may allow development of new simple approaches and methods to improve treatment of patients with brain damage.

\section{Acknowledgements}

The work was supported by NIH grant NS36154 and AHA grant $0250522 \mathrm{~N}$ to E.G. and internal UMMC funds. Provide list of individuals who contributed in the work and grant details.

\section{Conflicts of interest}

There are no conflicts of interests to disclose.

\section{References}

1. Moretti A, Ferrari F, Villa RF. Neuroprotection for ischaemic stroke: Current status and challenges. Pharmacol Ther. 2015;146:23-34.

2. O'Collins VE, Macleod MR, Donnan GA, et al. 1,026 experimental treatments in acute stroke. Ann Neurol. 2006;59(3):467-477.

3. Hahn CD, Manlhiot C, Schmidt MR, et al. Remote ischemic perconditioning: a novel therapy for acute stroke? Stroke. 2011;42(10):2960 2962.

4. Hasseldam H, Hansen-Schwartz J, Munkholm N, et al. Remote postconditioning reduces hypoxic damage early after experimental stroke. Neurol Res. 2013;35(4):336-343.

5. Iadecola C, Anrather J. Stroke research at a crossroad: asking the brain for directions. Nat Neurosci. 2011;14(11):1363-1368.

6. Dirnagl U, Simon RP, Hallenbeck JM. Ischemic tolerance and endogenous neuroprotection. Trends Neurosci. 2003;26(5):248-254.

7. Dirnagl U, Becker K, Meisel A. Preconditioning and tolerance against cerebral ischaemia: from experimental strategies to clinical use. Lancet Neurol. 2009;8(4):398-412.

8. Golanov EV, Zhou P. Neurogenic neuroprotection. Cell Mol Neurobiol. 2003;23(4-5):651-663.

9. Mandel M, Fonoff ET, Bor-Seng-Shu E, et al. Neurogenic neuroprotection: Future perspectives. Translational Neuroscience. 2012;3(4):399-412.

10. Wang J, Dong WW, Zhang WH, et al. Electrical stimulation of cerebellar fastigial nucleus: mechanism of neuroprotection and prospects for clinical application against cerebral ischemia. CNS Neurosci Ther. 2014;20(8):710-716.

11. Blix AS, Folkow B. Cardiovascular adjustments to diving in mammals and birds. In: Renkin EM and Michel CC (Eds.), Sect 2, The Cardiovascular System. Handbook of Physiology. Vol 4, American Physiological Society, Bethesda, pp.1983;917-945.

12. Butler PJ, Jones DR. Physiology of diving of birds and mammals. Physiol Rev. 1997;77(3):837-899.

13. Gooden BA. Mechanism of the human diving response. Integr Physiol Behav Sci. 1994;29(1):6-16. 
14. Brown CM, Sanya EO, Hilz MJ. Effect of cold face stimulation on cerebral blood flow in humans. Brain Res Bull. 2003;61(1):81-86.

15. Dormer KJ, Stone HL. Interaction of fastigial pressure response and depressor response to nasal perfusion. J Auton Nerv Syst. 1980;2(3):269280 .

16. McCulloch PF, Faber KM, Panneton WM. Electrical stimulation of the anterior ethmoidal nerve produces the diving response. Brain Res. 1999;830(1):24-31.

17. Panneton WM. Trigeminal mediation of the diving response in the muskrat. Brain Res. 1991;560(1-2):321-325.

18. Panneton WM. The Mammalian diving response: an enigmatic reflex to preserve life? Physiology (Bethesda). 2013;28(5):284-297.

19. Andersson JP, Liner MH, Fredsted A, et al. Cardiovascular and respiratory responses to apneas with and without face immersion in exercising humans. J Appl Physiol. 2004;96(3):1005-1010.

20. Castellini JM. Life under water: Physiological adaptations to diving and living at sea. Comprehensive Physiology. 2012;2:1889-1919.

21. Elsner R, Gooden B. Diving and asphyxia. A comparative study of animals and man. Monogr Physiol Soc. 1983;40:1-168.

22. Wolf S. The bradycardia of the dive reflex - a possible mechanism of sudden death. Trans Am Clin Climatol Assoc. 1964;76:192-200.

23. de Bruijn R, Richardson M, Schagatay E. Oxygen-conserving effect of the diving response in the immersed human. Diving Hyperb Med. 2009;39(4):193-199.

24. Alboni P, Alboni M, Gianfranchi L. Diving bradycardia: a mechanism of defence against hypoxic damage. $J$ Cardiovasc Med (Hagerstown). 2011;12(6):422-427.

25. Gooden BA. Why some people do not drown. Hypothermia versus the diving response. Med J Aust. 1992;157(9):629-632.

26. Waite PME. Trigeminal sensory system. In: Paxinos G (Ed.), The rat nervous system. (3rd edn), Elsevier, Amsterdam. 2004;pp.817-851.

27. Zhang F, Iadecola C. Stimulation of the fastigial nucleus enhances EEG recovery and reduces tissue damage after focal cerebral ischemia. $J$ Cereb Blood Flow Metab. 1992;12(6):962-970.

28. Glickstein SB, Ilch CP, Golanov EV. Electrical stimulation of the dorsal periaqueductal gray decreases volume of the brain infarction independently of accompanying hypertension and cerebrovasodilation. Brain Res. 2003;994(2):135-145.

29. Golanov EV, Reis DJ. Neuroprotective electrical stimulation of cerebellar fastigial nucleus attenuates expression of periinfarction depolarizing waves (PIDs) and inhibits cortical spreading depression. Brain Res. 1999;818(2):304-315.

30. Zhou P, Qian L, Glickstein SB, et al. Electrical stimulation of cerebellar fastigial nucleus $(\mathrm{FN})$ protects rat brain from staurosporine-induced apoptosis in vitro. Society for Neuroscience. 2000;26(1-2):-285.13.

31. Reis DJ, Kobylarz K, Yamamoto S, et al. Brief electrical stimulation of cerebellar fastigial nucleus conditions long-lasting salvage from focal cerebral ischemia: conditioned central neurogenic neuroprotection. Brain Res. 1998;780(1):161-165.

32. Popp A, Jaenisch N, Witte OW, et al. Identification of ischemic regions in a rat model of stroke. PLoS One. 2009;4(3):e4764.

33. Golanov EV, Reis DJ. Contribution of cerebral edema to the neuronal salvage elicited by stimulation of cerebellar fastigial nucleus after occlusion of the middle cerebral artery in rat. $J$ Cereb Blood Flow Metab. 1995;15(1):172-174.

34. Hossmann KA. The two pathophysiologies of focal brain ischemia: implications for translational stroke research. J Cereb Blood Flow Metab. 201232(7):1310-1316.
35. Duverger D, MacKenzie ET. The quantification of cerebral infarction following focal ischemia in the rat: influence of strain, arterial pressure, blood glucose concentration, and age. J Cereb Blood Flow Metab. 1988;8(4):449-461.

36. Golanov EV, Yamamoto S, Reis DJ. Reduction in focal cerebral infarction by stimulation of cerebellum is independent of changes in cerebral blood flow. J Cereb Blood Flow Metab. 1993;13(Suppl 1):S13.

37. Kapinya KJ, Prass K, Dirnagl U. Isoflurane induced prolonged protection against cerebral ischemia in mice: a redox sensitive mechanism? Neuroreport. 2002;13(11):1431-1435.

38. Xiang HF, Cao DH, Yang YQ, et al. Isoflurane protects against injury caused by deprivation of oxygen and glucose in microglia through regulation of the Toll-like receptor 4 pathway. J Mol Neurosci. 2014;54(4):664-670.

39. Schallner N, Ulbrich F, Engelstaedter $\mathrm{H}$, et al. Isoflurane but Not Sevoflurane or Desflurane Aggravates Injury to Neurons In Vitro and In Vivo via p75(NTR)-NF-kappa B Activation. Anesth Analg. 2014;119(6):1429-1441

40. Butcher KS, Hachinski VC, Wilson JX, et al. Cardiac and sympathetic effects of middle cerebral artery occlusion in the spontaneously hypertensive rat. Brain Res. 1993;621(1):79-86.

41. Cechetto DF. Experimental cerebral ischemic lesions and autonomic and cardiac effects in cats and rats. Stroke. 1993;24(12 Suppl):I6-I9.

42. Butcher KS, Cechetto DF. Insular lesion evokes autonomic effects of stroke in normotensive and hypertensive rats. Stroke. 1995;26(3):459 465.

43. Pac-Soo CK, Ma D, Wang C, et al. Specific actions of halothane, isoflurane, and desflurane on sympathetic activity and A delta and C somatosympathetic reflexes recorded in renal nerves in dogs. Anesthesiology. 1999;91(2):470-478.

44. Seagard JL, Hopp FA, Bosnjak ZJ, et al. Sympathetic efferent nerve activity in conscious and isoflurane-anesthetized dogs. Anesthesiology. 1984;61(3):266-270.

45. Perl ER. Function of dorsal root ganglion neurons: an overview. In: Scott SA (Ed.), Sensory neurons: diversity, development, and plasticity. Oxford University Press, New York, USA. 1992;p.3-23.

46. Heindl S, Struck J, Wellhoner P, et al. Effect of facial cooling and cold air inhalation on sympathetic nerve activity in men. Respir Physiol Neurobiol. 2004;142(1):69-80.

47. Greif R, Laciny S, Rajek A, et al. Blood pressure response to thermoregulatory vasoconstriction during isoflurane and desflurane anesthesia. Acta Anaesthesiol Scand. 2003;47(7):847-852.

48. Picker O, Scheeren TWL, Arndt JO. Inhalation anaesthetics increase heart rate by decreasing cardiac vagal activity in dogs. Br J Anaesth. 2001;87(5):748-754.

49. Toader E, Cividjian A, Quintin L. Isoflurane suppresses central cardiac parasympathetic activity in rats: a pilot study. Minerva Anestesiol. 2011;77(2):142-146.

50. Kinoshita T, Nagata S, Baba R, et al. Cold-water face immersion per se elicits cardiac parasympathetic activity. Circ J. 2006;70(6):773-776.

51. Hu JW, Sessle BJ. Properties of functionally identified nociceptive and nonnociceptive facial primary afferents and presynaptic excitability changes induced in their brain stem endings by raphe and orofacial stimuli in cats. Exp Neurol. 1988;101(3):385-399.

52. Peppel P, Anton F. Responses of rat medullary dorsal horn neurons following intranasal noxious chemical stimulation: effects of stimulus intensity, duration, and interstimulus interval. $J$ Neurophysiol. 1993;70(6):2260-2275. 
53. Amano N, Hu JW, Sessle BJ. Responses of neurons in feline trigeminal subnucleus caudalis (medullary dorsal horn) to cutaneous, intraoral, and muscle afferent stimuli. J Neurophysiol. 1986;55(2):227-243.

54. Dogan A, Rao AM, Başkaya MK, et al. Effects of ifenprodil, a polyamine site nmda receptor antagonist, on reperfusion injury after transient focal cerebral ischemia. J Neurosurg. 1997;87(6):921-926.

55. Nakagomi T, Kanemitsu H, Takagi K, et al. Effect of L-arginine and n-gnitro-1-arginine on delayed neuronal death in the gerbil hippocampus. Neurol. 1997;19(4):426-430.

56. Goadsby PJ, Duckworth JW. Effect of stimulation of trigeminal ganglion on regional cerebral blood flow in cats. Am J Physiol. 1987;253(2 Pt 2):R270-R274.

57. Goadsby PJ, Knight YE, Hoskin KL, et al. Stimulation of an intracranial trigeminally-innervated structure selectively increases cerebral blood flow. Brain Res. 1997;751(2):247-252.

58. Messlinger K, Hanesch U, Kurosawa M, et al. Calcitonin gene related peptide released from dural nerve fibers mediates increase of meningeal blood flow in the rat. Can J Physiol Pharmacol. 1995;73(7):1020-1024.

59. Golanov EV, Sitton M, Shiflett JM, et al. Rat model of diving reflex. FENS Forum Abstracts. 2004;2:A059.6.

60. Shiflett JM, Parent AD, Esposito AD, et al. Diving reflex: role of the subthalamic vasodilator area in cerebral blood flow adjustment. Soc Neurosci. 2003;236.5.

61. Reis DJ, Golanov EV, Galea E, et al. Central neurogenic neuroprotection: central neural systems that protect the brain from hypoxia and ischemia. Ann N Y Acad Sci. 1997;835:168-186.

62. Golanov EV, Yamamoto S, Reis DJ. Electrical stimulation of cerebellar fastigial nucleus fails to rematch blood flow and metabolism in focal ischemic infarctions. Neurosci Lett. 1996;210(3):181-184.
63. Glickstein SB, Ilch CP, Reis DJ, et al. Stimulation of the subthalamic vasodilator area and fastigial nucleus independently protects the brain against focal ischemia. Brain Research. 2001;912(1):47-59.

64. Craig AD, Dostrovsky JO. Differential projections of thermoreceptive and nociceptive lamina I trigeminothalamic and spinothalamic neurons in the cat. J Neurophysiol. 2001;86(2):856-870.

65. Mantyh PW. The ascending input to the midbrain periaqueductal gray of the primate. J Comp Neurol. 1982;211(1):50-64.

66. Trouerbach J, Duprez D, De Buyzere M, et al. Cardiovascular responses elicited by different simulated diving manoeuvres. Eur J Appl Physiol Occup Physiol. 1994;68(4):341-344.

67. Chochinov AH, Baydock BM, Bristow GK, et al. Recovery of a 62 year-old man from prolonged cold water submersion. Ann Emerg Med. 1998;31(1):127-131.

68. Huckabee HC, Craig PL, Williams JM. Near drowning in frigid water: a case study of a 31-year-old woman. J Int Neuropsychol Soc. 1996;2(3):256-260.

69. Perk L, Borger van de Burg F, Berendsen HH, et al. Full recovery after 45 min accidental submersion. Intensive Care Med. 2002;28(4):524.

70. Schmidt U, Fritz KW, Kasperczyk W, et al. Successful resuscitation of a child with severe hypothermia after cardiac arrest of 88 minutes. Prehosp Disaster Med. 1995;10(1):60-62.

71. Suominen P, Baillie C, Korpela R, et al. Impact of age, submersion time and water temperature on outcome in near-drowning. Resuscitation. 2002;52(3):247-254. 